\title{
AROMATIC HYDROCARBONS IN THE BILUO CO OIL SHALE OF THE SHUANGHU AREA, NORTHERN TIBETAN PLATEAU, AND THEIR IMPLICATIONS
}

\author{
CHANGJUN JI ${ }^{(\mathrm{a})}$, GUOQING XIA ${ }^{(\mathrm{a})^{*}}$, HAISHENG YI ${ }^{(\mathrm{a}, \mathrm{b})}$, \\ XINHE WU $^{(\mathrm{c})}$, QILAI LI ${ }^{(\mathrm{a})}$, LINGLING MAO ${ }^{(\mathrm{d})}$, \\ CHAOGANG FANG ${ }^{(\mathrm{e})}$
}

(a) Institute of Sedimentary Geology, Chengdu University of Technology, Chengdu 610059, China

(b) State Key Laboratory of Oil and Gas Reservoir Geology and Exploitation, Chengdu University of Technology, Chengdu 610059, China

(c) Oil \& Gas Survey, CGS, Beijing 100029, China

(d) Chongqing Institute of Geology and Mineral Resources, Chongqing 400042, China

(e) Nanjing Institute of Geology and Mineral Resource, Nanjing 210016, China

\begin{abstract}
The organic-rich marine sediments commonly referred to as black shales were deposited in the Qiangtang basin, northern Tibet. Although achievements in the respective researches have been remarkable, the depositional environment, source of organic matter, thermal maturity and biodegradation, which played a significant role in the deposition of these sediments during the Early Toarcian, are still topics of discussion.

In this paper, the geochemical characteristics of aromatic hydrocarbons contained in bitumen B of oil shale samples from the Biluo Co section of the Shuanghu area, northern Tibet, are considered in detail. In the oil shale samples, 154 aromatic hydrocarbon compositions mainly falling into 12 aromatic hydrocarbon series were detected. Among them the phenanthrene series predominates, followed by the naphthalene series, each of the rest having a low abundance, and the aromatics distribution is represented by typical prepeaks. Various geochemical parameters of these aromatic hydrocarbons are calculated and used to deduce the depositional environment, as well as the origin and thermal maturity of the oil shale organic matter.

The composition of organic matter and the relative abundance of aromatic hydrocarbons in the Biluo Co oil shale shows that these were mainly derived from lower marine organisms. At the same time, the relatively low abundance of 1,2,5-TMNr, 1,2,5,6-TeMNr, pimanthrene, biphenyl and other compounds, which are known to be diagnostic biomarkers of terraneous higher plants, is indicative of some higher plants input too. The high relative abundance of the DBT and 9-MP series suggests that the Biluo Co oil shale deposited in a
\end{abstract}

\footnotetext{
* Corresponding author: e-mail xiaguoqing06@163.com
} 
marine reducing sedimentary environment. The ratios of $C_{26}$ (20S) $T A S / C_{28}$ (20S) TAS vs $\sum T A S / \sum A H s$ and $\sum D B T / \sum D B F$ vs $\sum T A S / \sum A H$ s also confirm this conclusion. Maturity parameters, such as $M P I_{l}, R c, B F / B e P$, 4-MDBT/ $\Sigma M D B T, D B T /(D B T+M D B T)$, etc., are indicative of the degree of maturity of organic matter.

Keywords: aromatic hydrocarbons, oil shale, Qiangtang basin, biomarker.

\section{Introduction}

The origin and maturity of crude oil and source rocks are the most important parameters for hydrocarbons exploration [1]. In general, saturated hydrocarbons are considered to discuss the origin and maturation of source rocks, while aromatic hydrocarbons are little taken into account to deal with thermal maturity [2-5], source of organic matter [6, 7], biodegradation $[8,9]$ and depositional environment [10].

There are mainly two types of oil shales found in the Tibetan Plateau. The overwhelming part of oil shales was deposited in the continental environment, leaving far behind those that accumulated in the marine environment and outcrop only in the Shuanghu and Shenglihe areas. Over the past decades, several researches have been carried out addressing the structural geology, paleogeography, paleobiology, trace elements, stable oxygen and carbon isotopes, organic geochemistry, etc., of marine oil shales. For example, saturated hydrocarbons in the Biluo Co oil shale of the Shuanghu area have been investigated by Lin et al. [11, 12]. At the same time, studies on aromatic hydrocarbons are very few. Therefore, in this article, geochemical characteristics of aromatic hydrocarbons contained in the chloroform bitumen B of oil shale samples from the Biluo Co section of the Shuanghu area were systematically investigated using gas chromatographic-mass spectrometric (GC-MS) analysis, to elucidate the origin and maturity of oil shale. The study on aromatic hydrocarbons in the Biluo oil shale provides further information about the shale.

\section{Geological background}

The Qiangtang basin is located in the northern Tibetan Plateau, between the Hoh Xil Basin-Bayan Har and Himalayan-Gandese Plates covering about $18 \times 10^{4} \mathrm{~km}^{2}$. This rhombus-shaped basin of east-west direction is the biggest marine oil shales reservoir in the Tibetan Plateau. The Qiangtang basin is a Mesozoic petroliferous deposit whose folded basement formed during the Devonian. It can be divided into five large first-order tectonic units, namely, the northern Qiangtang depression belt, the western uplift belt, the central uplift belt, the eastern uplift belt and the southern Qiangtang depression belt (Fig. 1). 


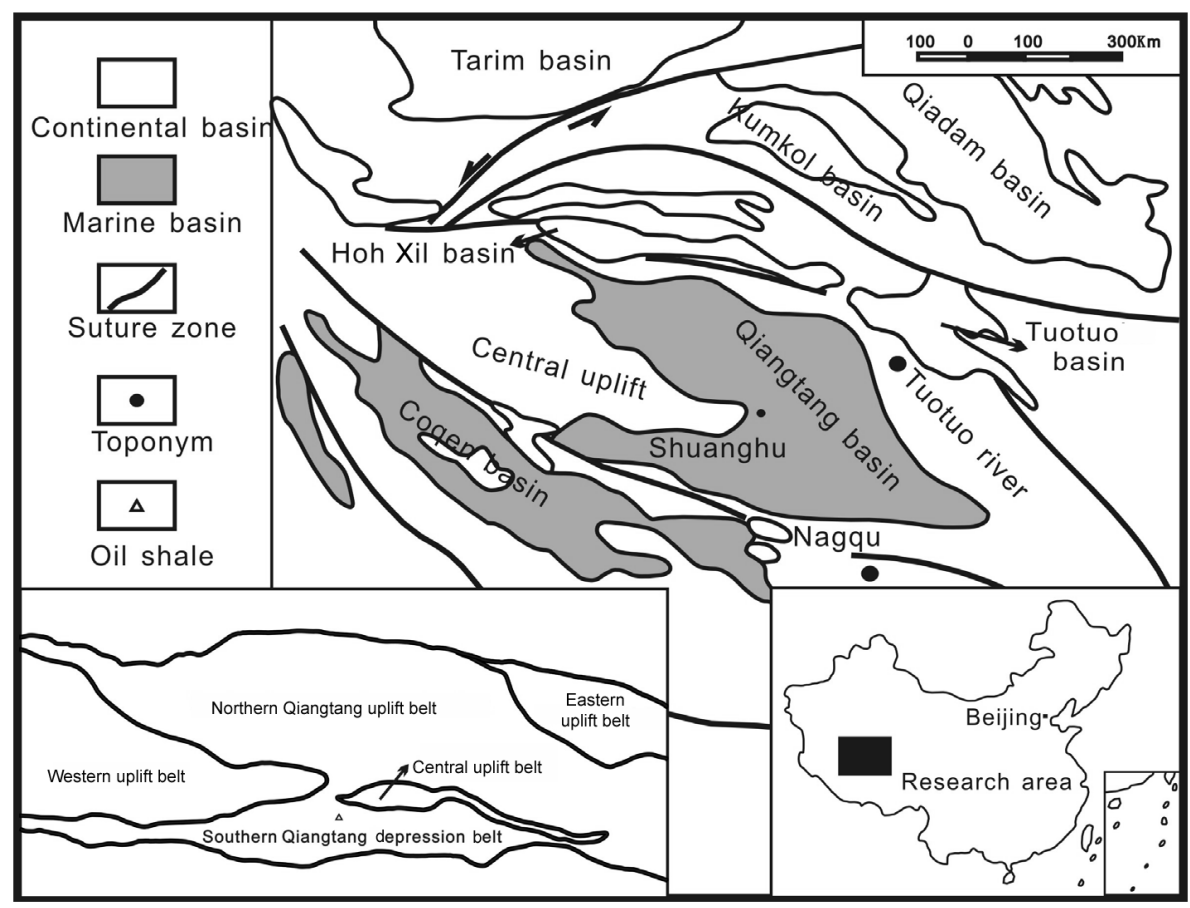

Fig. 1. Location map of the Qiangtang basin showing the research area.

The authors carried out detailed field investigations in the southeastern Biluo Co section of the Shuanghu area, which is about $45 \mathrm{~km}$ away from Shuanghu special district. The studied section with a length of $4 \mathrm{~km}$ along the east-west direction and a width of $3 \mathrm{~km}$ along the north-south direction has a wide thickness range. The whole succession is divided into three intervals characterized by different lithological types. From bottom to top these are gypsum, oil shale interbedded with limestone and mudstone, and marl interbedded with mudstone. Our thorough field investigations showed that oil shale is brown to dark in color and occurs as $0.2-2.0 \mathrm{~m}$ thick bituminous microlaminated beds [13].

The Biluo Co oil shale is characterized by a relatively high TOC content, with a maximum of $26.12 \%$, and type II kerogen. In addition, the organic matter sources mainly from lower aquatic organisms in admixture with plants. Furthermore, biomarkers maturity proxies show the samples to be of moderate maturity. Organic geochemical data of Biluo Co oil shale in the southern Qiangtang depression belt of the Qiangtang basin are presented in Table 1. The samples are rich in aromatic hydrocarbons, with a relative abundance of the aromatic fraction exceeding 30\% of total hydrocarbons, and in nearly half of the samples surpassing $50 \%$. Being major constituents of the soluble organic matter, polycyclic aromatic compounds carry important information about the origin and maturation of the oil shale. 
Table 1. Geochemical data of Biluo Co oil shale

\begin{tabular}{|c|c|c|c|c|c|c|c|c|c|}
\hline \multirow[b]{2}{*}{ 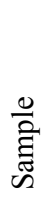 } & \multirow[b]{2}{*}{$\begin{array}{l}\partial^{\circ} \\
\circlearrowright \\
ٍ\end{array}$} & \multicolumn{4}{|c|}{$\begin{array}{c}\text { Chloroform bitumen "A" group component, } \\
\%\end{array}$} & \multirow{2}{*}{ 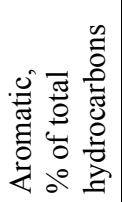 } & \multirow[b]{2}{*}{$\begin{array}{l}* \\
\text { 퐁 }\end{array}$} & \multirow[b]{2}{*}{ 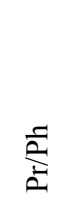 } & \multirow[b]{2}{*}{$\begin{array}{l}\stackrel{0}{ } \\
\stackrel{2}{\simeq}\end{array}$} \\
\hline & & $\begin{array}{c}\text { Saturated, } \\
\%\end{array}$ & $\begin{array}{l}\text { Aromatic, } \\
\%\end{array}$ & $\begin{array}{l}\text { Resin, } \\
\%\end{array}$ & $\begin{array}{l}\text { Asphaltene, } \\
\%\end{array}$ & & & & \\
\hline $\mathrm{S}_{28}$ & 2.79 & 33.46 & 19.38 & 38.36 & 8.57 & 36.68 & 0.99 & 1.52 & 1.06 \\
\hline $\mathrm{S}_{26}$ & 6.26 & 28.34 & 23.21 & 43.49 & 5.13 & 45.02 & 1.01 & 1.54 & 0.99 \\
\hline $\mathrm{S}_{23}$ & 9.61 & 23.65 & 28.28 & 33.89 & 14.14 & 54.46 & 0.98 & 1.59 & 0.88 \\
\hline $\mathrm{S}_{19}$ & 26.12 & 3.21 & 28.54 & 18.06 & 28.23 & 72.68 & 0.95 & 0.90 & 1.26 \\
\hline $\mathrm{S}_{13}$ & 13.74 & 9.52 & 31.42 & 34.99 & 23.80 & 76.75 & 1.00 & 0.86 & 1.06 \\
\hline$S_{11}$ & 5.63 & 8.67 & 28.69 & 40.49 & 21.80 & 76.79 & 0.96 & 0.77 & 0.93 \\
\hline $\mathrm{S}_{8}$ & 3.47 & 39.80 & 17.47 & 37.62 & 4.85 & 30.50 & 0.93 & 1.53 & 1.00 \\
\hline $\mathrm{S}_{4}$ & 1.87 & 34.72 & 16.59 & 43.27 & 4.92 & 32.33 & 0.90 & 1.22 & 0.98 \\
\hline
\end{tabular}

* $=\left(\mathrm{C}_{21}+6 \mathrm{C}_{23}+\mathrm{C}_{25}\right) /\left(4 \mathrm{C}_{22}+4 \mathrm{C}_{24}\right)$

\section{Analytical methods}

A total of eight oil shale samples from the Biluo Co section of the Shuanghu area in the southern Qiangtang depression belt of the Qiangtang basin were included in the study. The samples were first subjected to total organic carbon content and kerogen analysis.

Then the samples were extracted using dichlorodichloromethane in a Soxhlet apparatus $(72 \mathrm{~h})$. After asphaltene precipitation and fractionation by using column chromatography, saturated hydrocarbons were obtained by hexane flushing, then aromatic hydrocarbons by flushing with a mixture of dichloromethane and hexane $(2: 1, \mathrm{~V} / \mathrm{V})$. To avoid dissipation of light hydrocarbons of oil shale samples during processing, displacement fractionation was adopted to obtain saturated and aromatic hydrocarbons.

Gas chromatographic-mass spectrometric analyses of saturated and aromatic hydrocarbons were carried out on an Agilent 5973N Mass Selective Detector, HP-5 fused silica column $(60 \mathrm{~m} \times 0.32 \mathrm{~mm} \times 0.25 \mu \mathrm{m}$ film thickness), the carrier gas was helium at a flow rate of $1 \mathrm{~mL} / \mathrm{min}$. For analyzing the saturated hydrocarbons fraction, the GC oven was initially set at $100{ }^{\circ} \mathrm{C}$ for $5 \mathrm{~min}$, programmed to $220{ }^{\circ} \mathrm{C}$ at $4{ }^{\circ} \mathrm{C} / \mathrm{min}$ and then to $320{ }^{\circ} \mathrm{C}$ at $2{ }^{\circ} \mathrm{C} / \mathrm{min}$, with a final holding time of $25 \mathrm{~min}$. For analyzing the aromatic hydrocarbons fraction, the GC oven was initially set at $100^{\circ} \mathrm{C}$ for $5 \mathrm{~min}$ and then programmed to $320^{\circ} \mathrm{C}$ at $3{ }^{\circ} \mathrm{C} / \mathrm{min}$, with a final holding time of $25 \mathrm{~min}$. The temperature of feed ports was fixed at $300{ }^{\circ} \mathrm{C}$. The MS was operated with an ion source temperature of $320^{\circ} \mathrm{C}$ and ionization energy of $70 \mathrm{eV}$.

Through the above experimental process, there were eight oil shale samples for the analysis of saturated hydrocarbons (Table 1), four samples were used for aromatic hydrocarbons analysis (Table 2). 
Table 2. Relative AHs abundance, and source, sedimentary environment and maturity parameters of Biluo Co oil shale

\begin{tabular}{|c|c|c|c|c|c|c|}
\hline \multicolumn{3}{|c|}{ Sample } & B1 & B2 & B3 & B4 \\
\hline \multirow{5}{*}{$\begin{array}{l}\text { Relative } \\
\text { abundance }\end{array}$} & \multicolumn{2}{|c|}{$\sum \mathrm{Nr} / \sum \mathrm{P}$} & 0.47 & 0.15 & 0.26 & 0.32 \\
\hline & \multicolumn{2}{|c|}{$\sum \mathrm{P} / \sum \mathrm{AHs}$} & 20.90 & 56.10 & 50.16 & 50.42 \\
\hline & \multicolumn{2}{|c|}{$\sum \mathrm{TF} / \sum \mathrm{P}$} & 0.56 & 0.19 & 0.27 & 0.12 \\
\hline & \multicolumn{2}{|c|}{$\sum \mathrm{PAH} / \sum \mathrm{P}$} & 0.25 & 0.38 & 0.36 & 0.28 \\
\hline & \multicolumn{2}{|c|}{$\sum \mathrm{TAS} / \sum \mathrm{AHs}$} & 0.67 & 0.73 & 1.87 & 1.89 \\
\hline \multirow{3}{*}{$\begin{array}{c}\text { Source } \\
\text { parameters }\end{array}$} & \multirow{3}{*}{\multicolumn{2}{|c|}{$\begin{array}{c}1,2, \overline{-\mathrm{TMNr}} / \sum \mathrm{Nr}, \% \\
1,2,5,6-\mathrm{TeMNr} / \sum \mathrm{TeMN}, \% \\
\sum \mathrm{BPH} / \sum \mathrm{AHs}, \%\end{array}$}} & 5.03 & 3.90 & 4.96 & 3.62 \\
\hline & & & 8.41 & 6.33 & 7.14 & 8.17 \\
\hline & & & 1.58 & 1.65 & 1.18 & 2.02 \\
\hline \multirow{4}{*}{$\begin{array}{l}\text { Sedimentary } \\
\text { environment } \\
\text { parameters }\end{array}$} & Relative & DBT & 78.94 & 72.53 & 76.50 & 74.38 \\
\hline & abundance & DBF & 8.73 & 21.04 & 18.66 & 19.35 \\
\hline & of TF & $\mathrm{F}$ & 12.33 & 6.43 & 4.84 & 6.27 \\
\hline & \multicolumn{2}{|c|}{$\mathrm{TAS} \mathrm{C}_{26} / \mathrm{C}_{28}(20 \mathrm{~S})$} & 0.37 & 0.40 & 0.27 & 0.39 \\
\hline \multirow{5}{*}{$\begin{array}{c}\text { Maturity } \\
\text { parameters }\end{array}$} & \multicolumn{2}{|c|}{$\mathrm{MPI}_{1}$} & 0.41 & 0.44 & 0.42 & 0.44 \\
\hline & \multicolumn{2}{|c|}{$\mathrm{Rc}$} & 0.67 & 0.68 & 0.67 & 0.68 \\
\hline & \multicolumn{2}{|c|}{$\mathrm{BF} / \mathrm{BeP}$} & 0.21 & $\backslash *$ & 0.13 & 0.11 \\
\hline & \multicolumn{2}{|c|}{ 4-MDBT/ $\sum \mathrm{MDBT}$} & 0.53 & 0.66 & 0.61 & 0.52 \\
\hline & \multicolumn{2}{|c|}{$\mathrm{DBT} /(\mathrm{DBT}+\mathrm{MDBT})$} & 0.58 & 0.35 & 0.41 & 0.45 \\
\hline
\end{tabular}

I* not detected.

\section{Results and discussion}

\subsection{Distribution}

There are three peak groups of aromatic hydrocarbons (AHs) in the TICs of Biluo Co oil shale samples: a peak group of naphthalenes and alkyl naphthalenes, a peak group of phenanthrenes and alkyl phenanthrenes, and a peak group of aromatic sterenes and other polynuclear aromatic hydrocarbons (PAHs). Furthermore, on the basis of the distribution of aromatic hydrocarbons three peak groups can be distinguished. The first group of peaks appeared in the prepeak and is characterized by a very high abundance of naphthalenes and phenanthrenes. The second peak group was observed in the postpeak, having a very high concentration of aromatic sterenes and other PAHs. The third group of peaks appeared in double peaks and is characterized by a very high abundance of naphthalenes and other PAHs and aromatic sterenes, but a low concentration of phenanthrenes. In the TICs of Biluo Co oil shale samples, there is a very high concentration of naphthalenes in the first peak group and a high concentration of phenanthrenes in the second group of peaks. At the same time, the concentration of other PAHs and aromatic sterenes in the third peak group is very low. So, the three peak groups of aromatics distribution represented typical prepeaks, which is similar to the distribution of aromatic hydrocarbons in mature marine oils (Fig. 2). However, a previous research by the authors showed that biodegradation and fractionation during the migration process always resulted in a bulge, which means that the curve baseline of aromatic 
hydrocarbons in the TICs deviated from the abscissa. The more intensive the biodegradation became, the larger the "bulge" is, the lower the concentration of aromatic hydrocarbons is and the higher the abundance of triaromatic steranes is. Therefore, we can conclude that the biodegradation and fractionation during the migration process had a weak effect on the distribution of aromatic hydrocarbons in Biluo Co oil shale samples.

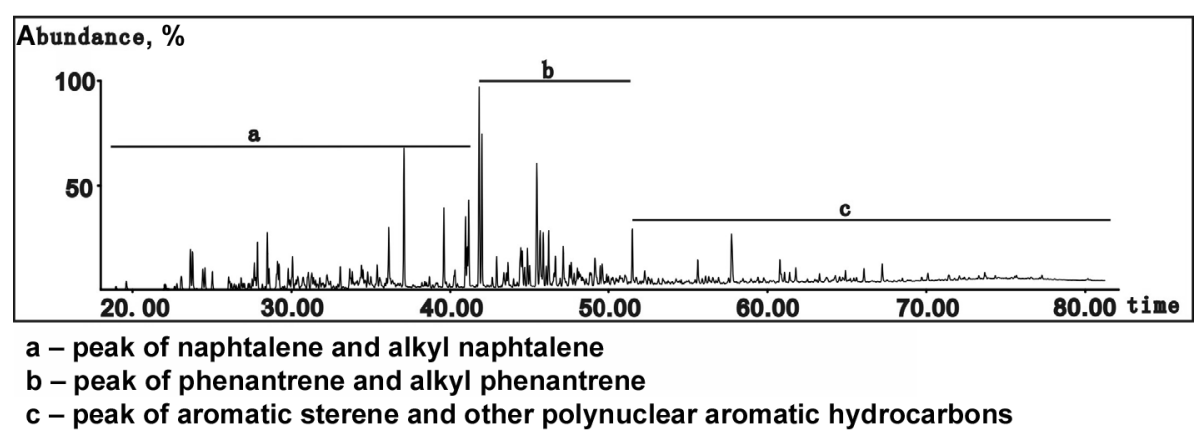

Fig. 2. Mass chromatograms of the aromatic fraction of sample B1 of Biluo Co oil shale, showing the distribution of aromatic hydrocarbons.

\subsection{Naphthalene series}

In Biluo Co oil shale samples, 38 aromatic hydrocarbon compositions were detected, dominated by the following seven series: naphthalene $(\mathrm{N})$, methylnaphthalene $(\mathrm{MN})$, dimethynaphthalene $(\mathrm{DMN})$, trimethynaphthalene $(\mathrm{TMN})$, tetramethynaphthalene $(\mathrm{TeMN})$, pentamethylnaphthalene $(\mathrm{PMN})$ and ethylnaphthalene (EN). The proportion of the alkyl naphthalene series is relatively high, the relative abundances being: $\mathrm{TMN}>\mathrm{DMN}>\mathrm{TeMN}>\mathrm{MN}>$ PMN (Fig. 3a). The shares of TMNr, TeMNr and PMNr are based on the increase of stable isomers in relation to lower-stability isomers and are thought to be determined by the 1,2-methyl shift and methyl transfer in the naphthalene carbon skeleton [14]. A more convenient way of representing the relationships between $\mathrm{TMNr}, \mathrm{TeMNr}$ and $\mathrm{PMNr}$ is using a ternary plot. If the three abundances are linearly related perfectly enough, all the samples should be plotted in a single point (maturity centre) in the ternary diagram [15]. However, the samples used in this research were located outside the maturity centre, which shows that the methylated naphthalenes were affected by a factor other than thermal stress. In addition, the maturity parameters of alkyl naphthalenes can be used for determination of the maturity of source rock and crude oil. For example, the ratios of $2,3,6-\mathrm{TMN} /(2,3,6-\mathrm{TMN}+1,2,5-$ trimethylnaphthalene) vs $1,3,6,7-\mathrm{TeMN} /(1,3,6,7-\mathrm{TeMN}+1,2,5,6-\mathrm{TeMN})$ fluctuate from low to high without being influenced by the fractional effect in migration. The samples investigated in this work are in the maturity stage (Fig. 3b). 


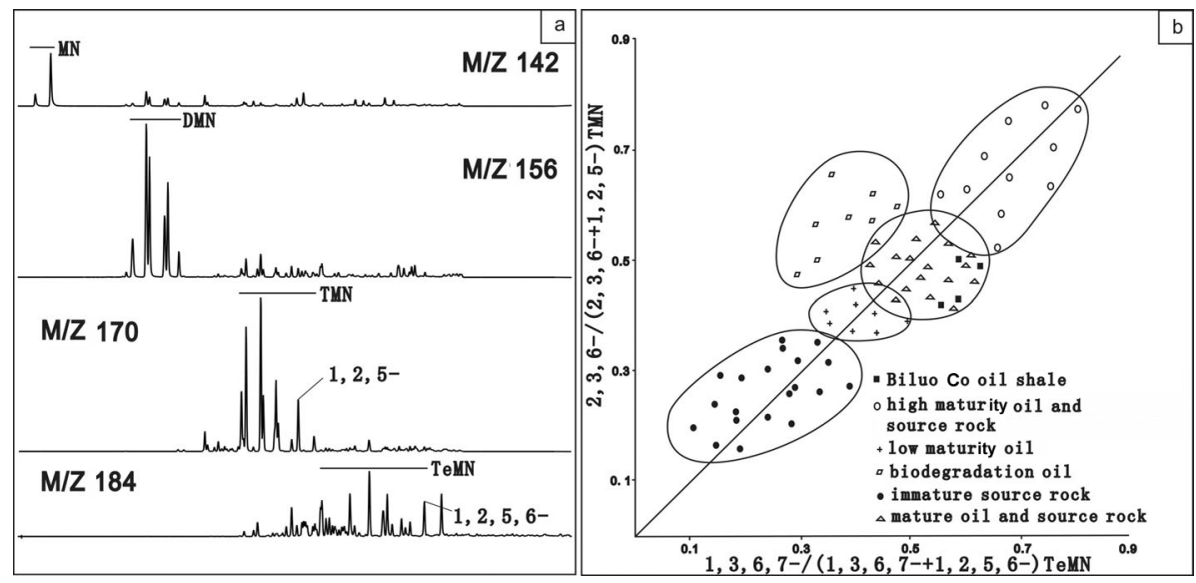

Fig. 3. (a) Mass chromatograms of the aromatic fraction of sample B2 of Biluo Co oil shale, showing the distribution of $\mathrm{MNr}, \mathrm{DMNr}, \mathrm{TMNr}$ and $\mathrm{TeMNr}(\mathrm{M} / \mathrm{Z} 142$, $156,170,184$ ); (b) plot of maturity parameters of TMNr and TeMNr, indicating the maturity of Biluo Co oil shale [19].

Several aromatic hydrocarbons, such as cadalene derived from sesquiterpenoids, and 1,2,5-TMNr and 1,2,5,6-TeMNr whose precursors were derived from higher plants, are indicative of general or more specific higher plant source $[16,17]$. However, cadalene was not detected in all samples, while the relative abundance of $1,2,5-\mathrm{TMNr}$ in $\mathrm{Nr}$ varied from $3.62 \%$ to $5.03 \%$ and that of $1,2,5,6-\mathrm{TeMNr}$ in TeMNr from $6.32 \%$ to $8.41 \%$. Both of these abundances are lower than the respective values of the marine oil in the Tarim basin, in whose case the relative abundance of $1,2,5-\mathrm{TMNr}$ in $\mathrm{Nr}$ is about $5 \%$ and that of $1,2,5,6-\mathrm{TeMNr}$ in $\mathrm{TeMNr}$ below $10 \%$. At the same time, the relative abundance of 1,3,5,7-TeMN, 1,3,6,7-TeMN and $1,4,6,7-\mathrm{TeMN}$ is lower than that of continental oil [18]. Based on the respective parameters, the Biluo Co oil shale has been derived from lower aquatic organisms with a small amount of higher plants.

\subsection{Phenanthrene series}

The phenanthrene series is mainly associated with the maturity of crude oil and source rocks [20]. However, the abundant phenanthrenes are the precursors of the phenanthrene series, and retenes or pimanthrenes were derived from higher plants, which contributed to the depositional environment and origin. While naphthalenes were derived from higher plants, phenanthrenes may be of low hydrobiological origin. In the oil shale samples investigated, the relative abundance of the phenanthrene series in aromatic hydrocarbons varies between $20.90 \%$ and $56.10 \%$, being on average $44.40 \%$, and the series comprises phenanthrene (P), methylphenanthrene (MP), dimethylphenanthrene (DMP), trimethylphenanthrene (TMP) (Fig. 4a) and ethylphenanthrene (EP). 


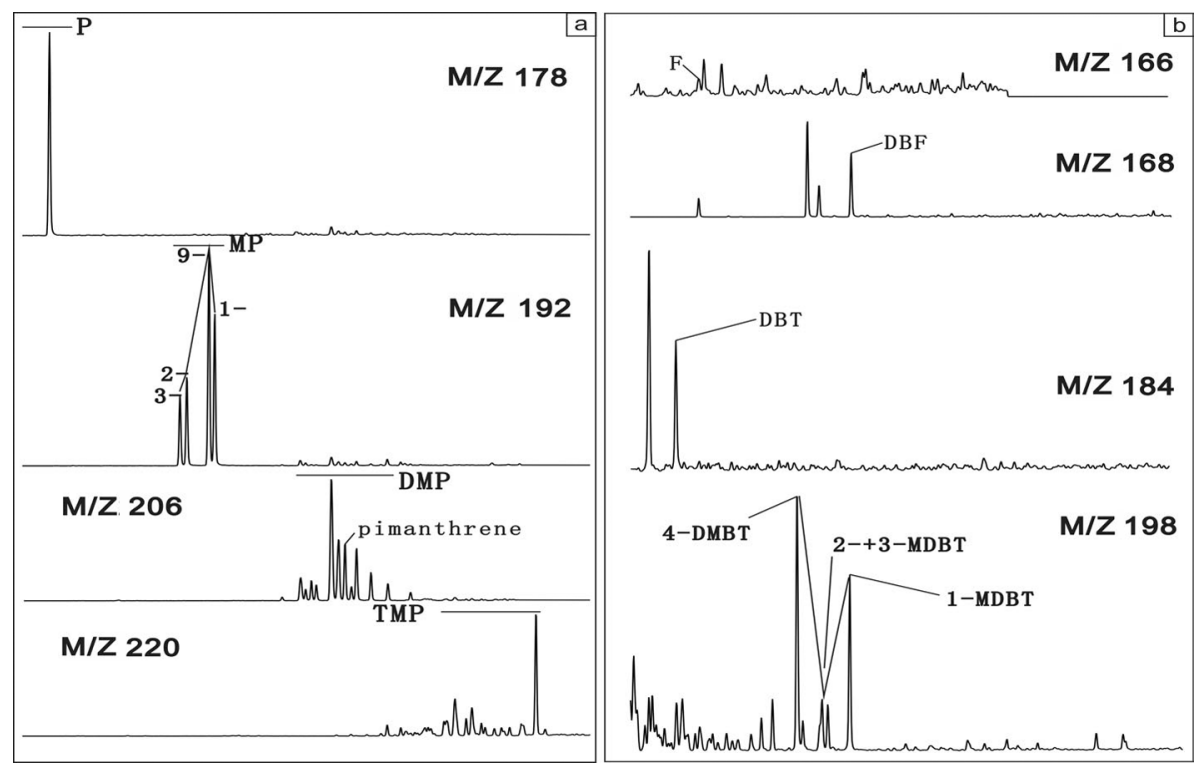

Fig. 4. (a) Mass chromatograms of the aromatic fraction of sample B3 of Biluo Co oil shale, showing the distribution of P, MP, DMP and TMP (M/Z 178, 192, 206, 220); (b) mass chromatograms of the aromatic fraction of sample B4 of Biluo Co oil shale, showing the distribution of F, DBF, DBT and MDBT (M/Z 166, 168, 184, 198).

The Biluo Co oil shale is characterized by the most abundant $\mathrm{P}$, and the relative abundance of MP as 9-MP $>1-\mathrm{MP}>2-\mathrm{MP}>3-\mathrm{MP}$, which resembles an inverted V. The MP series is dominated by 9-MP, the total abundance of 3-MP and 2-MP being much lower than that of 9-MP and 1-MP. The higher abundance of 9-MP has been reported to be due to marine source and is not associated with maturity [21, 22]. Furthermore, by scanning electron microscopy, abundant coccolithophores have been found in the Biluo Co oil shale, which indicates the contribution of the abundant phenanthrene series. Although retenes were not detected, we discovered a certain amount of pimanthrenes. The above-mentioned biomarkers indicate that the organic matter of Biluo Co oil shale is mainly derived from algae with a minor input of higher plants.

The compounds substituted in $\alpha$ position are less stable than related isomers with $\beta$-substitution patterns. Consequently, the values of the $\beta / \alpha$ concentration ratios for specific groups of compounds often vary with increasing degree of thermal maturation. Based on the methyl phenanthrene index [23], the maturity parameter utilizes the relative abundance of phenanthrene and methyl phenanthrene yields calculated vitrinite reflectance (VRc\%) ranging from 0.67 to 0.68 . This value is lower than the vitrinite reflectance $(\mathrm{Ro} \%)$, but similar to that of mature crude oil of the Nanpu Sag in the Bohai Bay basin $[24,25]$. This means that the Biluo Co oil shale is in 
the maturity stage. The reason other than maturity, which influenced the methyl phenanthrene index, will require further study.

\subsection{Aromatic sterene series and other PAHs}

\subsubsection{Triaromatic steranes series}

The $\mathrm{C}_{26-28}$ isomers of the triaromatic steranes (TAS) series are very resistant to biodegradation and were only degraded under extreme conditions [26]. In this work, the preferential depletion of $\mathrm{C}_{20-22}$ triaromatic sterane isomers has been established. The relatively high abundance of triaromatic steranes indicates the sedimentary environment of saline lake or immature to low maturity oil. Meng et al. put forward that the more salty the water in the saline lake is, the higher the abundance of the triaromatic steranes series in the aromatic hydrocarbons of crude oil is [27]. Wang reported that all crude oils in the Jiyang depression were characterized by the relative abundance of $\mathrm{C}_{26}$ (20S) TAS vs that of $\mathrm{C}_{28}$ (20S) TAS, which indicated the sedimentary environment and origin of source rocks [28]. However, the $\mathrm{C}_{28}$ TAS appeared in a freshwater environment and the $\mathrm{C}_{26}$ TAS was usually formed in brackish or saline water. Our investigation showed that the relative abundance of TAS and $\mathrm{C}_{26}(20 \mathrm{~S}) \mathrm{TAS} / \mathrm{C}_{28}(20 \mathrm{~S})$ TAS are very low. Using some data from [29] to construct charts depicted in Figure 5, the Biluo Co oil shale is shown to have deposited in a marine sedimentary environment. At the same time, the chart in Figure 5b may be used for classification of source rocks and crude oils originating from different sedimentary environments.

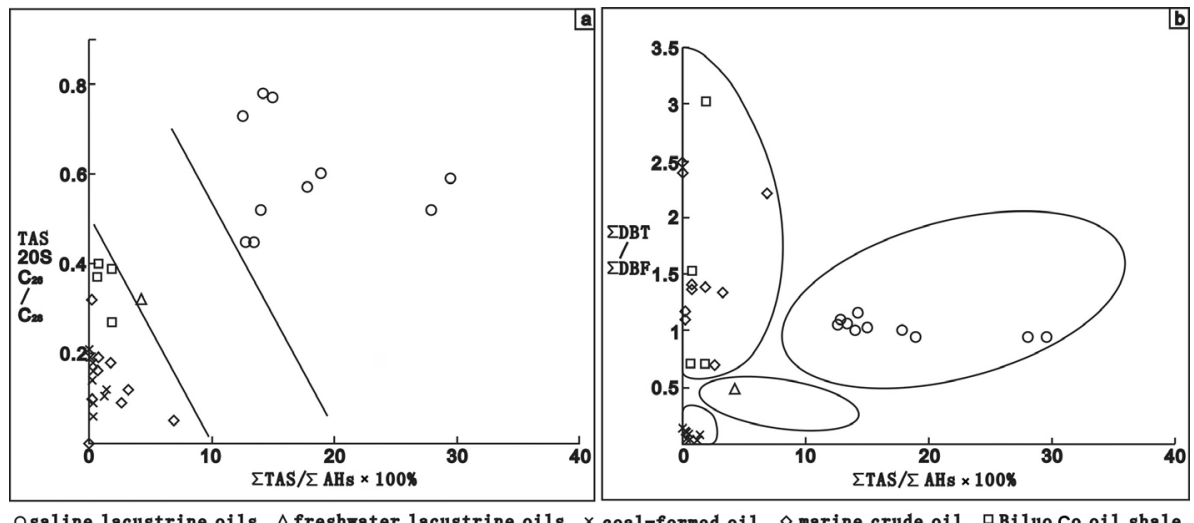

Fig. 5. (a) Plots of the relative abundance of $\mathrm{C}_{26}$ (20S) TAS vs that of $\mathrm{C}_{28}(20 \mathrm{~S})$ TAS $\times 100$ for different genetic types of oil; (b) plots of the ratio of $\sum \mathrm{DBT} / \sum \mathrm{DBF}$ vs that of $\sum \mathrm{TAS} / \sum \mathrm{AHs} \times 100$ for different genetic types of oil. Both (a) and (b) indicate that the Biluo Co oil shale was deposited in a marine environment (some data come from [29]). 


\subsubsection{Terfluorene series}

The terfluorene series indicates the depositional environment and maturity of crude oil and source rock. Particularly, the abundant dibenzothiophene series, including dibenzothiophene (DBT), methyldibenzothiophene (MDBT), dimethyldibenzothiophene (DMDBT) and trimethyldibenzothiophene (TMDBF), in marine oil and carbonates originates from the sulfocompounds of the high branched chain isoprenoid present in the strongly reducing environment (Fig. 4b). With increased maturity, MSF induces methyl rearrangement and demethylation. During methyl rearrangement, 1-MDBT, 2-MDBT and 3-MDBT transform to 4-MDBT, and in demethylation, MDBT transforms to DBT. In the samples investigated in the current work, there is a certain amount of terfluorenes (TFs), their distribution being DBT $<4$-MDBT. 4-MDBT is present in the highest concentration, while the abundance of $\sum$ DMDBT is higher than that of $\sum$ MDBT. The relative abundance of MDBT is 4-MDBT $>(2+3)$-MDBT $>1$-MDBT, being like a "V". These characteristics are typical of all crude oils of Ordovician source rocks in the Tarim basin, but the maturity parameters 4-MDBT/ $/$ MDBT $(0.52-0.66)$ and DBT/(DBT + MDBT) (0.35-0.58) are lower than those of high maturity to overmature Ordovician crude oils in the Tarim basin, and similar to those of mature Ordovician source rocks in Dagang Oilfield and Cretacic source rocks in the Coqen basin, Tibet [30,31]. So, the Biluo Co oil shale is in the maturity stage.

The relative abundance of dibenzothiophene (SF) in TFs, which include fluorene (F), dibenzothiophene (DBT) and dibenzofuran (DBF), is very high, even up to $78.94 \%$ (Fig. $4 \mathrm{~b}$ ). The previous research by Lin showed that these components have the same predecessor, but DBT and DBF resulted from the $\alpha$-position carbon atom of a five-membered ring of $\mathrm{F}$ and were replaced by a sulfur atom in the reducing environment, or by an oxygen atom in the weak oxidation-oxidation environment. Lin investigated the relation between TFs distribution and sedimentary environment in crude oil and source rock samples collected from different basins. $\mathrm{He}$ found that the relative abundance of DBT in TFs in marine crude oil or marine source rock was more than 50\% [32]. The Biluo Co oil shale was deposited in the marine reducing environment, which is evidenced by the fact that the relative abundance of SF in it is higher than $50 \%$ (Table 2).

\subsubsection{Other PAHs (four- or five-membered ring compounds) series}

Other PAHs are diverse compounds consisting of two or more fused aromatic rings. They are present in the extracts of crude oil and source rock as markers of maturity, hydrocarbon generation materials and sedimentary environment [33]. Primary PAHs are almost impossible to conserve in the geological history, but some PAHs originating from higher plants, for example, fluoranthene (FL), benzofluoranthene, benzo(e)pyrene (BeP), pyrene $(\mathrm{PY})$, perylene $(\mathrm{Pe})$, biphenyl $(\mathrm{BPH})$, etc., can be saved. In the 
studied samples, other PAHs were detected in low abundance, but PY was not detected at all. The $\mathrm{BF} / \mathrm{BeP}$ ratio ranges from 0.11 to 0.21 , which is lower than that of mature crude oil and source rock from the Shenglihe and Qaidam basins in China (the respective ratio of both of them is about $0.3)$. No BF was detected either. The relative abundance of BPH in PAHs varies from $1.18 \%$ to $2.02 \%$, which indicates that these compounds were derived from the lignin of higher plants. Both of the $\mathrm{BF} / \mathrm{BeP}$ and $\sum \mathrm{BPH} / \sum \mathrm{AHs}$ ratios are low, suggesting that there is a certain amount of higher plant resource input and that the Biluo Co oil shale is in the maturity stage.

\section{Conclusions}

154 aromatic hydrocarbon compositions were detected in four Biluo Co oil shale samples. The compounds mainly fall into the following 12 aromatic hydrocarbon series: naphthalene $(\mathrm{m} / \mathrm{z} 128, \mathrm{~m} / \mathrm{z} 142, \mathrm{~m} / \mathrm{z} 156, \mathrm{~m} / \mathrm{z} 170$, $\mathrm{m} / \mathrm{z} 184, \mathrm{~m} / \mathrm{z}$ 198), phenanthrene (m/z 178, m/z 192, m/z 206, m/z 220), benzopyrene ( $\mathrm{m} / \mathrm{z} 252)$, fluoranthene $(\mathrm{m} / \mathrm{z} 202, \mathrm{~m} / \mathrm{z} 216)$, dibenzothiophene $(\mathrm{m} / \mathrm{z} 184, \mathrm{~m} / \mathrm{z} 198, \mathrm{~m} / \mathrm{z} 212, \mathrm{~m} / \mathrm{z} 226)$, benzonaphthothiophene $(\mathrm{m} / \mathrm{z} 234)$, dibenzofuran $(\mathrm{m} / \mathrm{z} 168, \mathrm{~m} / \mathrm{z} 182, \mathrm{~m} / \mathrm{z} 196)$, fluorene $(\mathrm{m} / \mathrm{z} 166, \mathrm{~m} / \mathrm{z} 180$, $\mathrm{m} / \mathrm{z}$ 194), chrysene (m/z 228, m/z 242, m/z 256), biphenyl (m/z 154, m/z $168, \mathrm{~m} / \mathrm{z} 182)$, triaromatic sterane $(\mathrm{m} / \mathrm{z} 231)$ and benzohopane $(\mathrm{m} / \mathrm{z} 191)$. The biomarkers distribution and some parameters indicate that the Biluo Co oil shale has been derived from predominantly lower aquatic organisms mixed with a small amount of terrestrial higher plants deposited in a marine reducing environment, and that its organic matter has evolved maturity.

\section{Acknowledgements}

This research was supported by the Research Institute of Petroleum Exploration and Development, PetroChina, and the Open Foundation of the Key Laboratory for Sedimentary Basins and Oil and Gas Resources, Ministry of Land and Resources, Chengdu, China (Grant No zdsys2014002). The authors are grateful to Tang, Y. J. for performing the GC-IRMS analysis, and to Dr. Xia, G. Q., Dr. Wu, C. H., Dr. Chen, L. and Dr. Da, X. J. for carrying out field work. 


\section{REFERENCES}

1. Guo, X. W., He, S. Aromatic hydrocarbons as indicators of origin and maturation for light oils from Panyu lower uplift in Pearl River Mouth basin. J. Earth Sci., 2009, 20(5), 824-835.

2. Alexander, R., Kagi, R. I., Rowland, S. J., Sheppard, P. N., Chirila, T. V. The effects of thermal maturity on distributions of dimethylnaphthalenes and trimethylnaphthalenes in some ancient sediments and petroleums. Geochim. Cosmochim. Ac., 1985, 49(2), 385-395.

3. Radke, M. Organic geochemistry of aromatic hydrocarbons. In: Advances in Petroleum Geochemistry (Brooks, J., Welte, D., eds.). Academic Press, London, 1987.

4. Radke, M. Application of aromatic compounds as maturity indicators in source rocks and crude oils. Mar. Petrol. Geol., 1988, 5(3), 224-236.

5. Peters, K. E., Walters, C. C., Moldowan, J. M. The Biomarker Guide. Cambridge University Press, Cambridge, 2005.

6. Alexander, R., Bastow, T. P., Kagi, R. I., Singh, R. K. Identification of 1,2,2,5-tetramethyltetralin and 1,2,2,5,6-pentamethyltetralin as racemates in petroleum. J. Chem. Soc., Chem. Commun., 1992, 23, 1712-1714.

7. Strachan, M. G., Alexander, R., Kagi, R. I. Trimethylnaphthalenes in crude oils and sediments: Effects of source and maturity. Geochim. Cosmochim. Ac., 1988, 52(5), 1255-1264.

8. Fisher, S. J., Alexander, R., Kagi, R. I. Biodegradation of alkylnaphthalenes in sediments adjacent to an off-shore petroleum production platform. Polycycl. Aromat. Comp., 1996, 11(1-4), 35-42.

9. Asif, M., Grice, K., Fazeelat, T. Assessment of petroleum biodegradation using stable hydrogen isotopes of individual saturated hydrocarbon and polycyclic aromatic hydrocarbon distributions in oils from the Upper Indus Basin, Pakistan. Org. Geochem., 2009, 40(3), 301-311.

10. Pu, F., P., Philip, R. P., Zhenxi, L., Guangguo, Y. Geochemical characteristics of aromatic hydrocarbons of crude oils and source rocks from different sedimentary environments. Org. Geochem., 1990, 16(1-3), 427-435.

11. Lin, J. H., Yi, H. S., Li, Y. Characteristics of biomarker compounds and its implication of Middle Jurassic oil shale sequence in Shuanghu Area, Northern Tibet Plateau. Acta Sedimentol. Sinica, 2001, 19(2), 287-292 (in Chinese with English abstract).

12. Lin, J. H., Yi, H. S., Zou, Y. R. Biomarkers of marine and continental oil shales, the Zangbei Plateau. Geochimica, 2004, 33(1), 57-64 (in Chinese with English abstract).

13. Chen, L., Yi, H. S., Hu, R. Z., Zhong, H., Zou, Y. R. Organic geochemistry of the Early Jurassic oil shale from the Shuanghu area in northern Tibet and the Early Toarcian oceanic anoxic event. Acta Geol. Sin-Engl., 2005, 79(3), 392-397.

14. van Aarssen, B. G. K., Bastow, T. P., Alexander, R., Kagi, R. I. Distributions of methylated naphthalenes in crude oils: indicators of maturity, biodegradation and mixing. Org. Geochem., 1999, 30(10), 1213-1227.

15. Sivan, P., Datta, G. C., Singh, R. R. Aromatic biomarkers as indicators of source, depositional environment, maturity and secondary migration in the oils of Cambay Basin, India. Org. Geochem., 2008, 39(11), 1620-1630. 
16. Radke, M., Rullkötter, J., Vriend, S. P. Distribution of naphthalenes in crude oils from the Java Sea: Source and maturation effects. Geochim. Cosmochim. Ac., 1994, 58(17), 3675-3685.

17. van Aarssen, B. G. K., Alexander, R., Kagi, R. I. Higher plant biomarkers reflect palaeovegetation changes during Jurassic times. Geochim. Cosmochim. Ac., 2000, 64(8), 1417-1424.

18. Li, J. G., Paul, P., Meng, Z. F., Liu, W. H., Zheng, J. J., Chen, G. J., Li, M., Wang, Z. Y. Aromatic compounds in crude oils and source rocks and their application to oil-source rock correlations in the Tarim basin, NW China. J. Asian Earth Sci., 2005, 25(2), 251-268.

19. Chen, Z. L., Li, S. J., Wang, Z. A study on maturity indicators of some aromatics in low-midmature thermal evolution zones. Acta Sedimentol. Sinica, 1997, 15(2), 192-197 (in Chinese with English abstract).

20. Stojanović, K., Jovančićević, B., Pevneva, G. S., Golovko, J. A., Golovko, A. K., Pfendt, P. Maturity assessment of oils from the Sakhalin oil fields in Russia: phenanthrene content as a tool. Org. Geochem., 2001, 32(5), 721-731.

21. Budzinski, H., Garrigues, P., Connan, J., Devillers, J., Domine, D., Radke, M., Oudins, J. L. Alkylated phenanthrene distributions as maturity and origin indicators in crude oils and rock extracts. Geochim. Cosmochim. Ac., 1995, 59(10), 2043-2056.

22. Zhang, L. P., Huang, D. P. Characteristics of polycyclic aromatic hydrocarbon associations in some marine source rocks. Petroleum Exploration and Development, 1997, 24(2), 11-14 (in Chinese with English abstract).

23. Radke, M., Welte, D. H. The methylphenanthrene index (MPI): a maturity parameter based on aromatic hydrocarbons. In: Proceedings of the International Meeting on Organic Geochemistry, 1983, 10, 504-512.

24. Boreham, C. J., Crick, I. H., Powell, T. G. Alternative calibration of the Methylphenanthrene Index against vitrinite reflectance: Application to maturity measurements on oils and sediments. Org. Geochem., 1988, 12(3), 289-294.

25. Meng, J. H., Zhang, M., Yao, M. J. Features of aromatic composition in crude under different sedimentary environments and its geochemical meanings. Journal of Oil and Gas Technology, 2008, 30(1), 228-231 (in Chinese with English abstract).

26. Volkman, J. K., Alexander, R., Kagi, R. I., Rowland, S. J., Sheppard, P. N. Biodegradation of aromatic hydrocarbons in crude oils from the Barrow Sub-basin of Western Australia. Org. Geochem., 1984, 6, 619-632.

27. Meng, Q. X., Zhang, S. L., Cui, M. Z. Distribution features of aromatics in lacustrine low-mature crude oils from different environments. Acta Sedimentol. Sinica, 1998, 17, 112-120 (in Chinese with English abstract).

28. Wang, P. R. GC-MS GlS of Biomarker. Petroleum Industry Press, Beijing, 1993 (in Chinese).

29. Meng, J. H., Liu, L. F., Zhang, M., Wang, Y. Indicative function of aromatic hydrocarbon in crude oil on depositional environment. Journal of China University of Mining \& Technology, 2011, 40, 901-907 (in Chinese with English abstract).

30. Liu, L. F. Geochemical Characteristics of Aromatic Hydrocarbons of Ordovician Limestone in Dagang Oil Field, Shandong Province. Petroleum University Publishing House, Shandong, 1998, 41-47 (in Chinese with English abstract). 
31. Ren, Y. J., Li, R. X. Geochemical characteristics of aromatic hydrocarbons of Lower Cretaceous limestone in Cuoqin Basin. Acta Sedimentol. Sinica, 2001, 19(2), 282-286 (in Chinese with English abstract).

32. Li, S. F., He, S. Geochemical characteristics of dibenzothiophene, dibenzofuran and fluorene and their homologues and their environmental indication. Geochimica, 2008, 37(1), 45-50 (in Chinese with English abstract).

33. Oramah, I. T. Polynuclear aromatic hydrocarbons in Dashiwei karst tiankeng (sinkholes), south China. Environmental Geosciences, 2008, 15(2), 75-83.

Presented by J. Qian and J. Kann

Received August 21, 2013 